\title{
Cytotoxic T lymphocyte-associated antigen 4 inhibition increases the antitumor activity of adoptive T-cell therapy when carried out with naïve rather than differentiated $T$ cells
}

\author{
TAKESHI ISHIKAWA ${ }^{1,2^{*}}$, SATOKO ADACHI $^{2 *}$, TETSUYA OKAYAMA ${ }^{1,2^{*}}$, SATOSHI KOKURA $^{1,3}$, \\ KATSURA MIZUSHIMA ${ }^{1}$, TOSHIFUMI DOI ${ }^{1}$, TATSUZO MATSUYAMA ${ }^{1}$, NAOYUKI SAKAMOTO ${ }^{1}$, \\ KAZUHIRO KATADA ${ }^{1}$, KAZUHIRO KAMADA ${ }^{1}$, KAZUHIKO UCHIYAMA ${ }^{1}$, OSAMU HANDA ${ }^{1}$, \\ TOMOHISA TAKAGI $^{1}$, YUJI NAITO ${ }^{1}$, YOSHITO ITOH $^{1}$ and TOSHIKAZU YOSHIKAWA $^{2}$
}

Departments of ${ }^{1}$ Molecular Gastroenterology and Hepatology, and ${ }^{2}$ Cancer ImmunoCell Regulation, Graduate School of Medical Science, Kyoto Prefectural University of Medicine; ${ }^{3}$ Kyoto Gakuen University, Kyoto, Japan

Received December 13, 2014; Accepted January 20, 2015

DOI: $10.3892 /$ or.2015.3815

\begin{abstract}
Although treatment with an antibody against cytotoxic T-lymphocyte-associated antigen 4 (CTLA-4) combined with multiple therapeutic interventions has been explored, the effect of combination therapy with CTLA-4 inhibition and adoptive T-cell therapy has not been determined. In the present study, our aim was to determine whether CTLA-4 inhibition, combined with adoptive transfer of $\mathrm{T}$ cells at different stages of differentiation, exhibits synergistic antitumor effects in a murine colon cancer model. Mice bearing subcutaneous tumors were administered adoptive T-cell transfer of CD62 $\mathrm{L}^{\text {high }}$ or CD62 ${ }^{\text {low }}$ cells combined with an anti-CTLA-4 antibody $(\alpha$-CTLA-4) or control immunoglobulin G. Subcutaneous tumors were harvested, and the antitumor effects and helper T-cell polarization were analyzed. CTLA-4 inhibition combined with CD62 $\mathrm{L}^{\text {high }}$ cell administration showed the strongest antitumor effect. Combination therapy increased the number of $\mathrm{CD}^{+}$cells within the tumor. Moreover, CTLA-4 inhibition induced polarization of T cells infiltrating the tumor toward the $\mathrm{T}$ helper 1 lineage, and suppressed the frequency of regulatory $\mathrm{T}$ cells within the tumor, particularly in combination with $\mathrm{CD} 62 \mathrm{~L}^{\text {high }} \mathrm{T}$-cell transfer. This is the first report demonstrating that the efficacy of $\alpha$-CTLA- 4 and adoptive T-cell transfer combination therapy depends on the state of
\end{abstract}

Correspondence to: Professor Satoshi Kokura, Kyoto Gakuen University, Kyoto 621-8555, Japan

E-mail: s-kokura@koto.kpu-m.ac.jp

${ }^{*}$ Contributed equally

Abbreviations: CTLA, cytotoxic T lymphocyte-associated antigen 4; Treg, regulatory $\mathrm{T}$ cell; Th, helper T; Teff, effector T cell; ADCC, antibody-dependent cellular cytotoxicity

Key words: CTLA-4 antibody, adoptive T-cell therapy, naïve T-cell, T helper 1 differentiation of the transferred T cells. Our data support the notion that a combination of $\alpha$-CTLA- 4 and adoptive T-cell transfer containing an abundance of naïve phenotype cells could potentially exert antitumor effects in a clinical setting.

\section{Introduction}

Antigen-specific response and tolerance to tumors of the immune system are regulated by multiple networks of stimulatory and inhibitory signals. Delivery of inhibitory signals to $\mathrm{T}$ cells mediated by cytotoxic T-lymphocyte antigen 4 (CTLA-4) may mediate the development of tumor antigenspecific T-cell tolerance. CTLA-4 is expressed on the cell surface of activated $\mathrm{T}$ cells and is critical to restrict cell cycle progression and inhibit the production of interleukin (IL)-2 (1). CTLA-4 presents a degree of sequence homology with the T-cell costimulatory molecule CD28 and binds with higher avidity and affinity than CD28 to its ligands, B7-1 and B7-2 (2). Consequently, CTLA-4 promotes the termination of immune responses by preventing continuous T-cell costimulation and activation (2). $\mathrm{CD}^{+}{ }^{+}$and $\mathrm{CD}^{+} \mathrm{T}$ cells not expressing CTLA-4 exhibit an activated phenotype and increased proliferation potential both in vitro and in vivo $(3,4)$. CTLA-4-deficient mice develop a CD28-dependent expansion of autoreactive $\mathrm{T}$ cells in lymph nodes, spleen and several peripheral organs, which leads to death within 4 weeks after birth due to diffuse lymphoproliferative disease (5).

Due to the central role of CTLA-4 in the inhibition of T-cell activation, targeting of this molecule holds great promise for several clinical applications. Clinical trials conducted with various anti-CTLA- 4 antibodies ( $\alpha$-CTLA- 4 ) demonstrated that selective inhibition of CTLA-4 enhances the endogenous antitumor immune response. The fully human antibodies tremelimumab and ipilimumab have been studied extensively in melanoma and were found to act by blocking the interaction of CTLA-4 with B7 ligands to enhance T-cell proliferation and activation (6-8). In a phase III study, tremelimumab administration did not improve overall survival when compared with dacarbazine chemotherapy (6). Conversely, ipilimumab 
administration improved survival in comparison with patients with melanoma previously treated with a peptide vaccine (7). Furthermore, a phase III study demonstrated that ipilimumab and dacarbazine combination therapy is more effective than dacarbazine treatment alone (8). Subsequently, ipilimumab was approved in 2011 for the treatment of unresectable or metastatic melanoma by regulatory agencies in the US and the European Union.

CTLA-4 inhibition combined with multiple therapeutic interventions in murine tumor models has been explored (9). Synergistic effects were demonstrated in combination with chemotherapy (10), radiation $(11,12)$, cryoablation (13) and surgery (14). These studies indicate that CTLA-4 inhibition can be an effective therapeutic strategy to extend and elicit the immune response in cancer-bearing hosts. Preclinical studies have demonstrated that CTLA-4 suppression is effective against tumors in combination with other immunotherapies such as cancer vaccines (15-18), cytosine-phosphate-guanine oligodeoxynucleotide (CpG-ODN) adjuvants $(18,19)$ and antibodies $(20,21)$. However, it is not clear whether CTLA-4 inhibition and adoptive T-cell transfer combination therapy is effective against tumors.

The state of differentiation of $\mathrm{T}$ cells is crucial to the success of adoptive T-cell therapy, and less-differentiated $\mathrm{T}$ cells are ideal due to their in vivo persistence, high proliferative potential, receptiveness to homeostatic and costimulatory signals, and their ability to target secondary lymphoid tissues and secrete IL-2 $(22,23)$. CTLA-4 suppression has the potential to enhance the activation of less-differentiated transferred $\mathrm{T}$ cells in vivo. In the present study, we evaluated whether a combination of CTLA-4 inhibition and transfer of adoptive $\mathrm{T}$ cells at different stages of differentiation exhibit synergistic antitumor effects in a murine colon cancer model.

\section{Materials and methods}

Mice and cell line. All experiments were performed according to the protocols approved by the Animal Care Committee of Kyoto Prefectural University of Medicine. BALB/c male mice were purchased from Shimizu Laboratory Supplies Co., Ltd. (Kyoto, Japan), fed a standard laboratory diet, and were provided with water ad libitum under standard laboratory conditions. Mice between 7 and 8 weeks of age were used for the subsequent experiments.

The colon-26 murine colon adenocarcinoma cell line was used. Cells were cultured in monolayer with RPMI-1640 medium supplemented with $10 \%$ fetal bovine serum (FBS), l-glutamine and penicillin/streptomycin at $37^{\circ} \mathrm{C}$ in a humidified atmosphere containing $5 \% \mathrm{CO}_{2}$.

Reagents. For in vivo CTLA-4 inhibition, purified hamster anti-mouse CD152 (CTLA-4; clone UC10-4F10, \#BE0032) immunoglobulin (Ig)G or hamster IgG control antibodies (\#BE0091) were purchased from Bio X Cell (West Lebanon, NH, USA).

Preparation of therapeutic CD62 $L^{\text {high }}$ and CD62 $L^{\text {low }} T$ cells. The effects of CTLA-4 inhibition combined with transfer of adoptive $\mathrm{T}$ cells at different stages of differentiation were determined. To this end, CD62 $\mathrm{L}^{\text {high }}$ and CD62 $\mathrm{L}^{\text {low }} \mathrm{T}$ cells were prepared for less-differentiated (naïve phenotype) and differentiated (effector phenotype) adoptive transfer therapy, respectively. $T$ cells were obtained from spleens harvested from 7-week-old male BALB/c mice sacrificed by cervical dislocation. Splenocytes were mechanically dissociated and strained through a $40-\mu \mathrm{m}$ nylon mesh to produce a single-cell suspension. $\mathrm{CD}^{+} \mathrm{T}$ cells were separated by AutoMACS Pro using the Pan $\mathrm{T}$ isolation kit (both from Miltenyi Biotec, Tokyo, Japan) and seeded on 12-well plates (Thermo Fisher Scientific K.K., Yokohama, Japan) previously coated with $5 \mu \mathrm{g} / \mathrm{ml}$ of mCD3 antibody (R\&D Systems, Rockville, MD, USA), and $5 \mu \mathrm{g} / \mathrm{ml}$ RetroNectin ${ }^{\circledR}$. Cells were cultured in GT-T503 medium (Takara Bio, Inc., Otsu, Japan) containing 10\% FBS, penicillin/streptomycin, nonessential amino acids, sodium pyruvate and 2-ME for 3 days $\left(1.5 \times 10^{6}\right.$ cells $/ 2.5 \mathrm{ml} /$ well $)$. Subsequently, cells were transferred into a T225 flask (BD Falcon, Franklin Lakes, NJ, USA) and cultured with GT-503 containing $100 \mathrm{U} / \mathrm{ml}$ recombinant mouse IL-2 and $10 \mathrm{ng} / \mathrm{ml}$ recombinant mouse IL-7 (both from R\&D Systems). Seven days after harvesting, CD62 $\mathrm{L}^{\text {high }}$ and CD62 $\mathrm{L}^{\text {low }}$ populations were sorted with a MACS CD62L $\mathrm{L}^{+}$ selection column (Miltenyi Biotec).

Adoptive cell transfer and $\alpha$-CTLA-4 administration. Male $\mathrm{BALB} / \mathrm{c}$ mice at 7-8 weeks of age were injected s.c. with $1 \times 10^{6}$ colon-26 cells. Mice ( $n=9$ for all groups) were treated with i.v. adoptive T-cell transfer ( $5 \times 10^{7}$ cells) 6 and 13 days after tumor challenge. $\alpha$-CTLA-4 or control IgG [100 $\mu \mathrm{g}$ in phosphatebuffered saline (PBS)] was delivered intraperitoneally 5, 8, 10,12 and 15 days after tumor challenge. The percentage of CD62 $\mathrm{L}^{+}$cells in the transferred population was confirmed by flow cytometry. Tumor growth was monitored twice a week, and tumor volume was expressed as $\left(\mathrm{a} \mathrm{x} \mathrm{b}^{2}\right) / 2$, where $\mathrm{a}$ is the largest and $b$ is the smallest diameter of the tumor. Mice were sacrificed by cervical dislocation 17 days after tumor inoculation.

Flow cytometry. The phenotype of the lymphocytes in the transferred cells and in the draining lymph nodes was analyzed by flow cytometry. For lymph node analysis, the tissue was mechanically dissociated and strained through a 40- $\mu$ m nylon mesh to produce a single-cell suspension.

Cells were stained with fluorescein isothiocyanate (FITC)-, phycoerythrin (PE)-, phycoerythrin-Texas Red (ECD)-, or phycoerythrin-cyanin (PC5)-conjugated monoclonal antibodies specific for CD3, CD4, CD8, CD62L (Beckman Coulter, Marseille, France), forkhead box P (Foxp)-3, and interferon (IFN) $-\gamma$ (both from eBioscience, San Diego, CA, USA). Five hours before cell harvesting, brefeldin A (BD Biosciences, San Jose, CA, USA) was added for intracellular blocking of IFN- $\gamma$. A single aliquot was thawed, and mononuclear cells were stained with fluorescence-conjugated antibodies and analyzed with a FACSCalibur flow cytometer (BD Biosciences). Data acquisition and analysis were conducted with the CellQuest software version 6.0 for Mac OS 10 (BD Biosciences).

Immunohistochemistry. Seventeen days after subcutaneous transplantation of colon-26 cells, tumors were harvested, fixed in formalin and analyzed by immunohistochemistry. For immunostaining, 4- $\mu \mathrm{m}$ sections were cut, deparaffinized and subjected to heat-induced epitope retrieval before incubation 


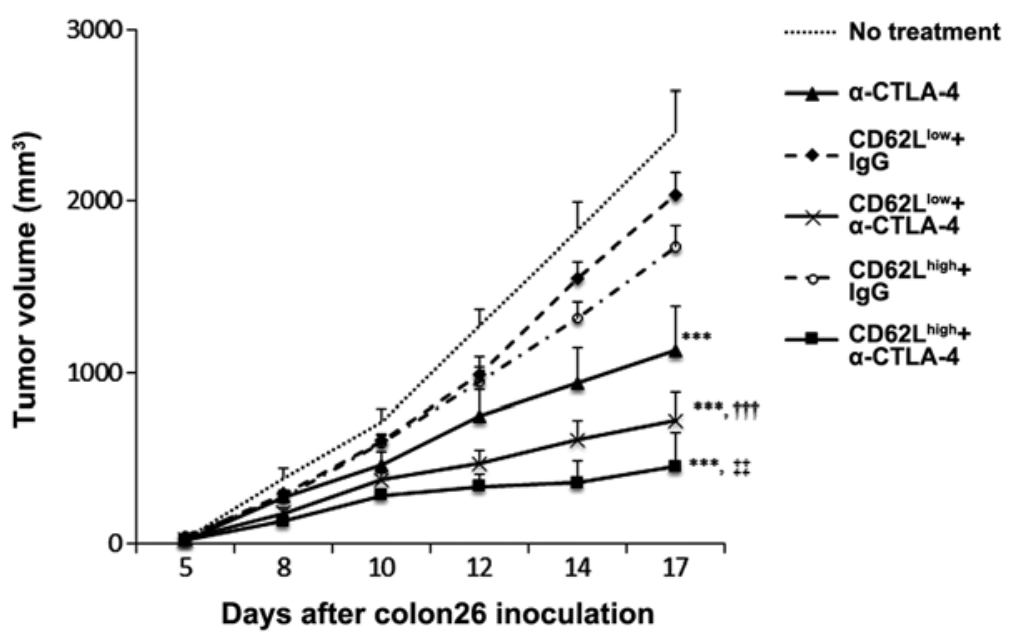

Figure 1. Effects of combination therapy with anti-CTLA-4 Ab and adoptive cell transfer on tumor growth. Tumor-bearing mice were treated with antiCTLA-4 Ab or control IgG (day 5, 8, 10, 12 and 15) combined with adoptive cell transfer (day 6 and 13) of CD62L ${ }^{\text {low }}$ or CD62 ${ }^{\text {high }}$ cells. Results of tumor

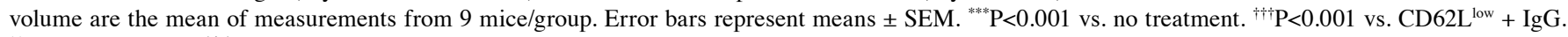
P $<0.01$ vs. CD62L $\mathrm{L}^{\text {high }}+$ IgG. CTLA-4, cytotoxic T-lymphocyte-associated antigen 4; IgG, immunoglobulin G.

with the antibodies. Sections were immersed in sodium citrate buffer at $\mathrm{pH} 7.0$ and heated in a high-pressure cooker, treated with $3 \% \mathrm{H}_{2} \mathrm{O}_{2}$ in methanol for $15 \mathrm{~min}$, and blocked with Dako Protein Block Serum-Free solution for $30 \mathrm{~min}$. Two consecutive sections were then incubated for 2-3 $\mathrm{h}$ at room temperature with a rabbit anti-CD3 antibody (ab5690; Abcam, Cambridge, MA, USA) and a rabbit anti-Foxp3 antibody (14-5773-82; eBioscience) at a dilution of 1:100 and 1:300, respectively. After incubation with anti-rabbit MAX-PO secondary antibody (Nichirei Bioscience, Tokyo, Japan), color development was performed using a DAB substrate kit (Nichirei Bioscience).

Detection of T-bet, GATA-3 and Foxp3 expression by western blot analysis. Subcutaneous tumors were harvested and frozen immediately. Total cell protein was extracted by thawing on ice and homogenizing at $4^{\circ} \mathrm{C}$ in a solution of $50 \mathrm{mmol} / \mathrm{l}$ Tris- $\mathrm{HCl}$, $\mathrm{pH} 7.6,300 \mathrm{mmol} / \mathrm{l} \mathrm{NaCl}, 0.5 \%$ Triton X-100, $10 \mu \mathrm{g} / \mathrm{ml}$ aprotinin, $10 \mu \mathrm{g} / \mathrm{ml}$ leupeptin, $1 \mathrm{mmol} / 1$ phenylmethylsulfonyl fluoride, $1.8 \mathrm{mg} / \mathrm{ml}$ iodoacetamide, $50 \mathrm{mmol} / \mathrm{l} \mathrm{NaF}$ and $1 \mathrm{mM}$ DTT. Equal quantities of protein $(25 \mu \mathrm{g})$ were added to lysis buffer containing protease inhibitors and boiled at $70^{\circ} \mathrm{C}$ for $10 \mathrm{~min}$. The proteins were separated by $10 \% \mathrm{NuPAGE}^{\circledR}$ Novex Bis-Tris Gel and electroblotted to nitrocellulose membranes (iBlot $^{\circledR}$ Transfer Stack) (both from Thermo Fisher Scientific, Hampton, NH, USA). Membranes were incubated in blocking buffer (AE-1475; ATTO Corporation, Tokyo, Japan) for $20 \mathrm{~min}$, followed by primary antibodies $(20 \mathrm{~h})$ raised against mouse T-bet (1:500 dilution, sc21003), GATA-3 (1:500 dilution, sc9009) (both from Santa Cruz Biotechnology Inc., Santa Cruz, CA, USA), Foxp3 (1:500 dilution, 320002; BioLegend, Inc., San Diego, CA, USA), tubulin (1:500 dilution, T9026; Sigma-Aldrich, St. Louis, MO, USA) in Tris-buffered saline containing $0.1 \%$ Tween-20 (TBS-T). Subsequently, membranes were incubated with secondary anti-mouse or rabbit antibodies (GE Healthcare, Tokyo, Japan) in TBS-T (diluted 1:10,000) for $50 \mathrm{~min}$ at room temperature. Immunocomplexes were detected using a commercial kit (ECL Plus; GE Healthcare
Bio-Sciences K.K., Tokyo, Japan) according to the manufacturer's recommendations.

Statistics. The results are presented as mean \pm SEM. Statistical significance of differences between means was analyzed by one-way ANOVA, followed by Tukey's multiple comparison test, and $\mathrm{P}<0.05$ indicates a statistically significant difference. All analyses were performed using the GraphPad Prism 4 program (GraphPad Software, Inc., La Jolla, CA, USA).

\section{Results}

Phenotype of transferred cells. CD62 $\mathrm{L}^{\text {high }}$ and CD62 $\mathrm{L}^{\text {low }}$ cells from mouse spleen were cultured, and before cell separation, double $\mathrm{CD}_{62} \mathrm{~L}^{+}$and $\mathrm{CD}^{+} \mathrm{T}$ cells contributed to $55 \%$ of the total cell population. After separation, the fractions of double $\mathrm{CD}_{62} \mathrm{~L}^{+}$and $\mathrm{CD}^{+} \mathrm{T}$ cells among total CD62 $\mathrm{L}^{\text {high }} \mathrm{T}$ cells from the first and second adoptive transfer were 92.16 and $96.78 \%$, respectively. In contrast, the fraction of double-positive T cells among total $\mathrm{CD}_{62} \mathrm{~L}^{\text {low }} \mathrm{T}$ cells was $26.63 \%$ in the first and $36.71 \%$ in the second adoptive transfer. Subsequently, we considered T-cell separation between CD62 $\mathrm{L}^{\text {high }}$ and CD62 $\mathrm{L}^{\text {low }}$ successful, and we used these cells for further analysis.

CTLA-4 inhibition enhances the therapeutic potential of adoptive T-cell transfer. To determine whether CTLA-4 inhibition enhances the antitumor effects of adoptive cell transfer, $1 \times 10^{6}$ colon- 26 cells were injected subcutaneously, followed by intravenous injection of CD62 $\mathrm{L}^{\text {high }}$ or CD62 $\mathrm{L}^{\text {low }} \mathrm{T}$ cells with or without administration of $\alpha$-CTLA-4. Tumor growth was monitored twice a week. The body weight of the mice was not affected by the procedure and did not change over time (data not shown). Administration of CD62 $\mathrm{L}^{\text {high }} \mathrm{T}$ cells exhibited a tendency toward higher antitumor activity than administration of CD62L ${ }^{\text {low }} \mathrm{T}$ cells (Fig. 1). $\alpha$-CTLA-4 monotherapy displayed significant antitumor activity. Administration of $\alpha$-CTLA- 4 combined with CD62L $\mathrm{L}^{\text {low }}$ or CD62L $\mathrm{L}^{\text {high }}$ cell administration enhanced the antitumor activity to a greater 

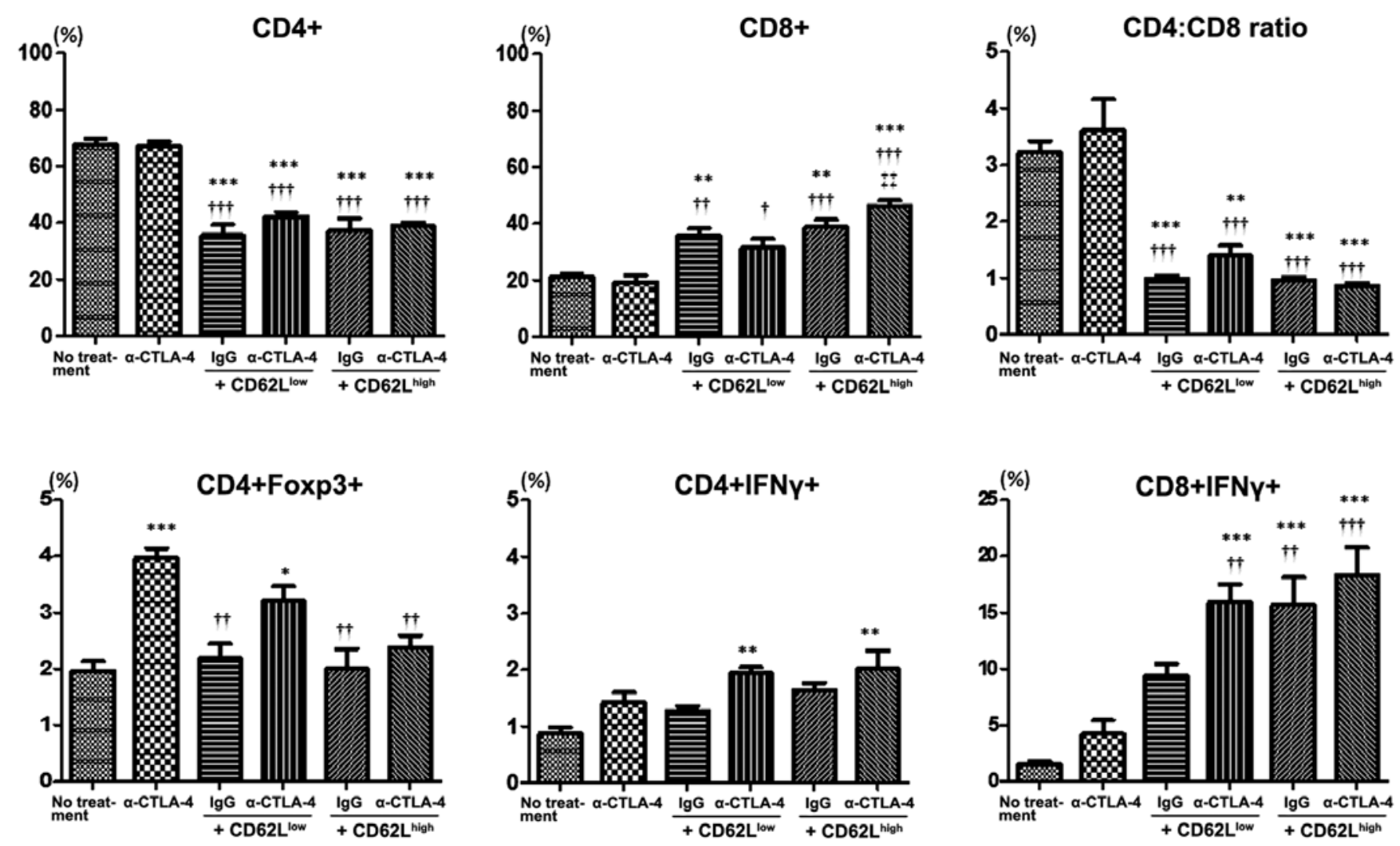

Figure 2. Flow cytometric analysis of lymphocytes from the spleen of control mice (no treatment), mice treated with anti-CTLA-4 Ab and mice treated with adoptive cell transfer (CD62 $\mathrm{L}^{\text {low }}$ or CD62 $\mathrm{L}^{\text {high }}$ subsets) combined with control IgG or anti-CTLA-4 Ab at day 17 after tumor challenge. The percentage of CD4 ${ }^{+}$ $\mathrm{CD}^{+}, \mathrm{CD}^{+} \mathrm{Foxp}^{+}, \mathrm{CD} 4^{+} \mathrm{IFN} \gamma^{+}$and $\mathrm{CD} 8^{+} \mathrm{IFN} \gamma^{+} \mathrm{T}$ cells was analyzed using flow cytometry ( $\mathrm{n}=3$ mice in each group). Error bars represent means $\pm \mathrm{SEM}$. ${ }^{*} \mathrm{P}<0.05,{ }^{* *} \mathrm{P}<0.01,{ }^{* * *} \mathrm{P}<0.001$ vs. no treatment. $\mathrm{P}<0.05,{ }^{{ }^{+} \mathrm{P}}<0.01,{ }^{\dagger \dagger} \mathrm{P}<0.001$ vs. anti-CTLA-4 Ab. ${ }^{*} \mathrm{P}<0.01$ vs. CD62L ${ }^{\text {low }}+$ anti-CTLA-4 Ab. CTLA-4, cytotoxic T-lymphocyte-associated antigen 4; IgG, immunoglobulin G.

extent than did administration of CD62 $\mathrm{L}^{\text {low }}$ or $\mathrm{CD} 62 \mathrm{~L}^{\text {high }}$ in combination with IgG injection $(\mathrm{P}<0.001)$. CTLA-4 suppression combined with administration of CD62 $\mathrm{L}^{\text {high }} \mathrm{T}$ cells exhibited a tendency toward a higher efficacy against tumors than injection of CD62L $\mathrm{L}^{\text {low }} \mathrm{T}$ cells, although the effect was not statistically significant.

Adoptive T-cell transfer and CTLA-4 inhibition modifies the population of lymphocytes within the spleen and draining lymph nodes. We assessed the phenotype of lymphocytes in the spleen and draining lymph nodes of tumor-bearing mice. In the spleen of mice subjected to adoptive T-cell transfer, the frequency of $\mathrm{CD} 4^{+}$lymphocytes was decreased whereas that of CD8-positive cells was increased (Fig. 2). The CD4/CD8 ratio was significantly lower in mice subjected to adoptive cell transfer than this ratio in the controls (no treatment) or mice injected with $\alpha$-CTLA- 4 . Monotherapy with $\alpha$-CTLA- 4 did not affect the frequency of CD4- and CD8-positive cells or the CD4/CD8 ratio in the spleen. The frequency of Tregs (CD4 ${ }^{+}$ and $\mathrm{Foxp}^{+}$) in the spleen was higher in mice treated with $\alpha$-CTLA- 4 than the frequency in the controls. The frequency of IFN- $\gamma$-producing cells in $\mathrm{CD}^{+}$lymphocytes was higher in mice subjected to $\alpha$-CTLA- 4 and adoptive cell transfer combination therapy when compared with the frequency in the control mice. The frequency of IFN- $\gamma$-producing cells among $\mathrm{CD} 8^{+}$lymphocytes was higher in the context of $\alpha$-CDLA- 4 and CD62 $\mathrm{L}^{\text {low }}$ adoptive transfer combination therapy, and in mice subjected to $\mathrm{CD}^{2} \mathrm{~L}^{\text {high }}$ cell transfer irrespective of CTLA-4 suppression, than under control conditions. The frequency in the context of $\alpha$-CTLA- 4 monotherapy or CD62L ${ }^{\text {low }}$ adoptive transfer was higher than under basal conditions, yet the effect reached statistical significance.

Similar trends were observed in draining lymph nodes (Fig. 3). The frequency of $\mathrm{CD} 4^{+} \mathrm{T}$ cells was decreased in mice administered CD62 $\mathrm{L}^{\text {high }} \mathrm{T}$ cells combined with control IgG or $\alpha$-CTLA-4 in comparison to control mice or mice subjected to $\alpha$-CTLA- 4 monotherapy. The frequency of $\mathrm{CD}^{+} \mathrm{T}$ cells was significantly higher in the context of adoptive CD62L $\mathrm{L}^{\text {low }}$ or $\mathrm{CD} 62 \mathrm{~L}^{\text {high }}$ transfer than under control conditions, and this effect was more pronounced in the mice subjected to CD62 $\mathrm{L}^{\text {high }} \mathrm{T}$-cell transfer than in those administered CD62L $\mathrm{L}^{\text {low }}$ $\mathrm{T}$ cells. The CD4/CD8 ratio was lower in mice treated with $\alpha$-CTLA- 4 or subjected to adoptive T-cell transfer, either alone or in combination, than this ratio in the control mice. The lowest CD4/CD8 ratio was observed in the mice subjected to $\mathrm{CD} 62 \mathrm{~L}^{\text {high }} \mathrm{T}$-cell transfer and $\alpha$-CTLA- 4 combination therapy. The frequency of Tregs increased in all mice treated with $\alpha$-CTLA- 4 or subjected to adoptive T-cell transfer. The frequency of IFN- $\gamma$-producing cells among CD4-positive lymphocytes was not affected by the treatments. Mice injected with $\alpha$-CTLA- 4 or T cells, either alone or in combination, exhibited a tendency toward a higher frequency of IFN- $\gamma$ producing cells among $\mathrm{CD} 8^{+}$lymphocytes than control mice, yet the effect did not reach statistical significance. 

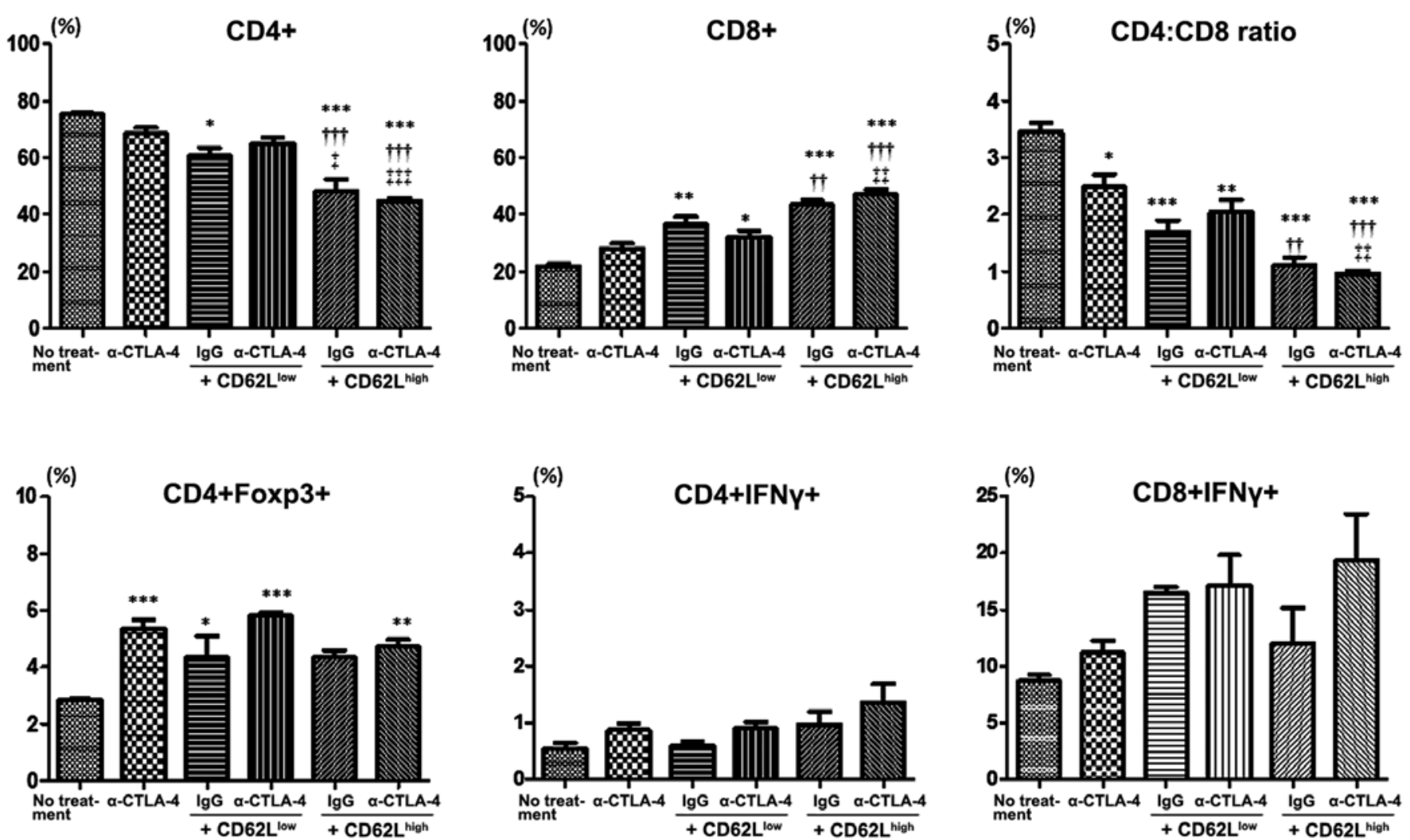

Figure 3. Flow cytometric analysis of lymphocytes from draining lymph nodes of control mice (no treatment), mice treated with anti-CTLA-4 Ab and mice treated with adoptive cell transfer (CD62 $\mathrm{L}^{\text {low }}$ or CD62 $\mathrm{L}^{\text {high }}$ subsets) combined with control IgG or anti-CTLA-4 Ab at day 17 after tumor challenge. The percentage of $\mathrm{CD}^{+}, \mathrm{CD}^{+}, \mathrm{CD} 4^{+} \mathrm{Foxp} 3^{+}, \mathrm{CD} 4^{+} \mathrm{IFN} \gamma^{+}$and $\mathrm{CD} 8^{+} \mathrm{IFN} \gamma^{+} \mathrm{T}$ cells was analyzed using flow cytometry ( $\mathrm{n}=3$ mice in each group). Error bars represent means \pm SEM. ${ }^{*} \mathrm{P}<0.05,{ }^{* *} \mathrm{P}<0.01,{ }^{* * *} \mathrm{P}<0.001$ vs. no treatment. ${ }^{\dagger} \mathrm{P}<0.01,{ }^{\dagger \dagger} \mathrm{P}<0.001$ vs. anti-CTLA-4 Ab. ${ }^{*} \mathrm{P}<0.01$ vs. CD62L ${ }^{\text {low }}+$ anti-CTLA-4 Ab. CTLA-4, cytotoxic T-lymphocyte-associated antigen 4; IgG, immunoglobulin G.

A

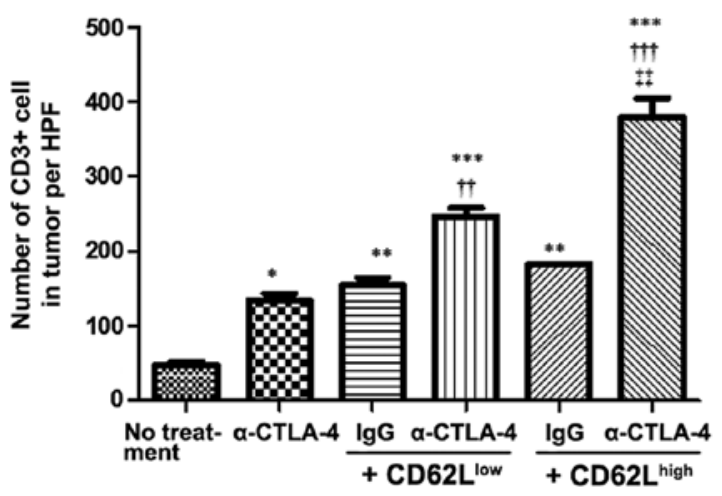

B

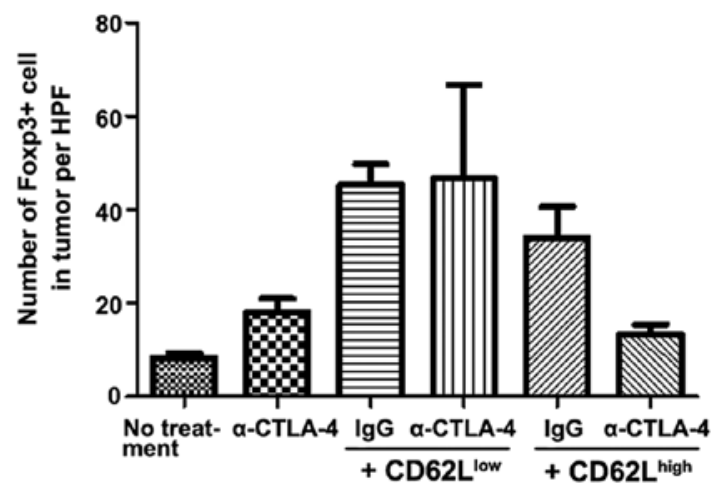

Figure 4. Immunohistological analysis of infiltrating T cells within the tumors of control mice (no treatment), mice treated with anti-CTLA-4 Ab and mice treated with adoptive cell transfer (CD62 $\mathrm{L}^{\text {low }}$ or $\mathrm{CD} 62 \mathrm{~L}^{\text {high }}$ subsets) combined with control IgG or anti-CTLA-4 Ab at day 17 after tumor challenge. The graph shows the average number of (A) $\mathrm{CD}^{+}$and (B) $\mathrm{CD} 4^{+} \mathrm{Foxp}^{+} \mathrm{T}$ cells within tumors counted in 3 random microscopic views under $\mathrm{x} 200$ magnification

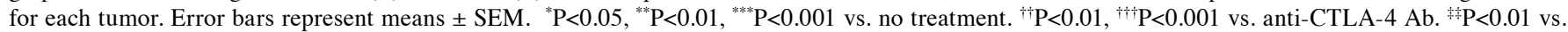
CD62L ${ }^{\text {low }}+$ anti-CTLA-4 Ab. HPF, high power field; CTLA-4, cytotoxic T-lymphocyte-associated antigen 4; IgG, immunoglobulin G.

CTLA-4 inactivation promotes T-cell migration and lowers the frequency of Foxp3-positive cells within the tumor. We assessed the number of infiltrating $\mathrm{T}$ cells within the tumor by immunohistochemistry. Quantitative analysis represents the mean counts from three high-power fields. The number of intratumoral $\mathrm{CD}^{+}$cells in mice subjected to $\alpha$-CTLA- 4 monotherapy, or to adoptive $\mathrm{CD} 62 \mathrm{~L}^{\text {low }}$ or $\mathrm{CD} 62 \mathrm{~L}^{\text {high }} \mathrm{T}$-cell transfer, either alone or in combination, was higher than in untreated controls (Fig. 4). $\alpha$-CTLA-4 and CD62L ${ }^{\text {low }}$ and CD62 $\mathrm{L}^{\text {high }}$ adoptive transfer promoted the migration of $\mathrm{CD} 3$ positive cells better than adoptive T-cell transfer combined with administration of control IgG. The number of $\mathrm{CD}^{+}$cells migrating within the tumor was the highest in mice subjected to $\alpha$-CTLA- 4 and CD62 $\mathrm{L}^{\text {high }}$ adoptive transfer combination 


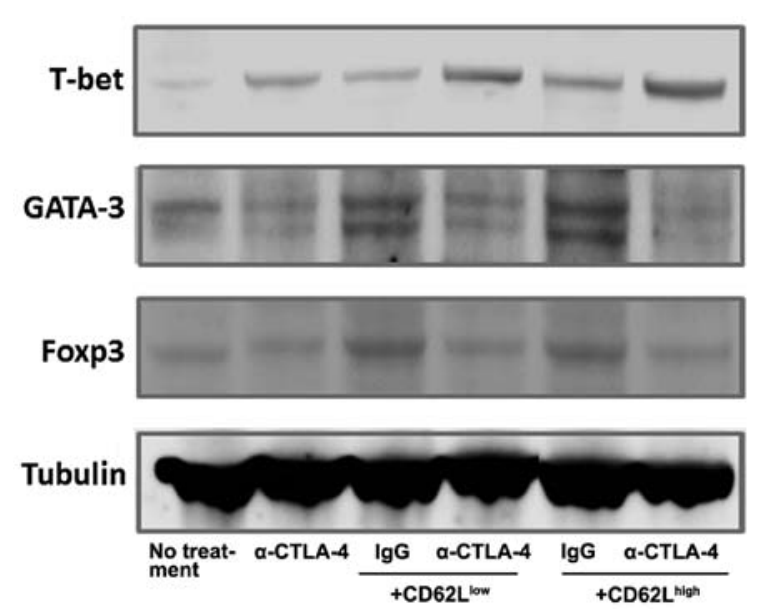

Figure 5. Western blot analysis of the expression of T-bet, GATA-3 and Foxp3 within tumors of the control mice (no treatment), mice treated with anti-CTLA-4 $\mathrm{Ab}$ and mice treated with adoptive cell transfer $\left(\mathrm{CD} 62 \mathrm{~L}^{\text {low }}\right.$ or CD62 $\mathrm{L}^{\text {high }}$ subsets) combined with control IgG or anti-CTLA-4 Ab at day 7 after tumor challenge. CTLA-4, cytotoxic T-lymphocyte-associated antigen 4; IgG, immunoglobulin $\mathrm{G}$.

therapy. The number of Foxp $3^{+}$cells within the tumor was higher in mice administered either CD62 $\mathrm{L}^{\text {low }}$ or CD62 $\mathrm{L}^{\text {high }}$ $\mathrm{T}$ cells than this number in the untreated mice. Mice administered $\alpha$-CTLA- 4 presented a tendency toward an increased number of intratumoral Foxp $3^{+}$cells, although the effect did not reach statistical significance. Administration of $\alpha$-CTLA- 4 reduced the number of Foxp3-positive cells in the mice administered CD62L ${ }^{\text {high }}$ but not CD62L ${ }^{\text {low }} \mathrm{T}$ cells.

CTLA-4 inhibition alters the expression of T-bet, GATA-3 and Foxp3 in tumors of mice subjected to adoptive T-cell transfer. Western blot analysis was performed to investigate helper $\mathrm{T}$ (Th) differentiation in the tumors. The differentiation of Th1 lymphocytes is associated with a specific transcription factor, T-bet, which is a key regulator of cytokine expression by Th1. The expression of T-bet was increased under all experimental conditions in comparison to basal conditions (Fig. 5). CTLA-4 inhibition and adoptive CD62 $\mathrm{L}^{\text {low }}$ and CD62 $\mathrm{L}^{\text {high }} \mathrm{T}$-cell transfer combination therapy enhanced the T-bet expression levels. T-bet expression was the highest in the mice treated with $\alpha$-CTLA-4 in combination with CD62 $\mathrm{L}^{\text {high }}$ cell transfer. Blocking CTLA- 4 attenuated the expression of the Th2 lineage transcription factor GATA3, whereas adoptive T-cell transfer had the opposite effect. CTLA-4 inhibition and CD62 $\mathrm{L}^{\text {low }}$ or CD62 $\mathrm{L}^{\text {high }}$ adoptive transfer combination therapy attenuated GATA3 expression. Foxp3 expression was higher in the mice subjected to adoptive T-cell transfer than that in the controls. Although CTLA-4 inactivation alone did not affect Foxp3 expression, $\alpha$-CTLA- 4 and adoptive T-cell transfer combination therapy attenuated Foxp3 expression in comparison to mice administered CD62 $\mathrm{L}^{\text {low }}$ and CD62 $\mathrm{L}^{\text {high }}$ cells combined with control IgG.

\section{Discussion}

The present study provides evidence that blocking CTLA-4 enhances the antitumor efficacy of adoptive T-cell transfer therapy, particularly when $\mathrm{CD} 62 \mathrm{~L}^{\text {high }} \mathrm{T}$ cells, characterized by a high frequency of naïve $T$ cells, were administered. Our results also indicate that $\alpha$-CTLA- 4 and adoptive T-cell transfer combination therapy increases the number of $\mathrm{CD}^{+}$cells within the tumor, and that CTLA-4 inhibition leads to polarization of tumor-infiltrating $\mathrm{T}$ cells toward the Th1 lineage. Furthermore, $\alpha$-CTLA- 4 combined with CD62 $\mathrm{L}^{\text {high }}$ yet not CD62 $\mathrm{L}^{\text {low }} \mathrm{T}$ cells decreased the frequency of Tregs within the tumor. Although CTLA-4 suppression combined with cancer vaccines $(15-18)$ and therapeutic antibodies $(20,21)$ is effective against tumors in preclinical models, there is limited evidence of a synergistic antitumor effect of CTLA-4 suppression and adoptive T-cell therapy $(24,25)$. This is the first report on the effects of $\alpha$-CTLA- 4 on Th polarization of tumor-infiltrating $\mathrm{T}$ cells following adoptive T-cell transfer, and suggests that the effects of combination therapy depend on the state of T-cell differentiation. These data may have important implications in the clinical application of $\alpha$-CTLA- 4 combined with adoptive T-cell therapy.

The exact mechanism mediating the antitumor effects of CTLA-4 inhibition remains undefined. Although antitumor activity of CTLA-4 suppression may be mediated by interference with the negative regulation of effector T-cell (Teff) function, recent reports suggest a secondary mechanism, wherein CTLA-4 inhibition affects Teff suppressive activity or mediates Treg depletion (25-27). In agreement with our results pertaining to the expression of $\mathrm{CD} 3$ and Foxp3, prior reports have demonstrated that CTLA-4 suppression decreases the number of Tregs within tumors, yet not those occurring in the draining lymph node $(25,26)$, and increases the Teff/Treg ratio, which suggests an imbalanced proliferation of Tregs over Teffs within the tumor microenvironment (28-30). Recently, Simpson et al demonstrated in a mouse model that $\alpha$-CTLA- 4 depletes tumor-infiltrating Tregs and that this effect is dependent on the presence of $\mathrm{Fc} \gamma$ receptor-expressing macrophages (25). These findings indicate that antibody-dependent cellular cytotoxicity (ADCC) is likely to be involved in Treg depletion in response to $\alpha$-CTLA- 4 . However, a hamster $\alpha$-CTLA- 4 was used in the present study, so that under these experimental conditions, $\alpha$-CTLA- 4 may decrease the number of Foxp3-positive cells by ADCC-independent mechanisms. Previous studies have demonstrated that induced Tregs, a subset of Tregs, develop as a consequence of activation of mature $\mathrm{T}$ cells under specific conditions in the tumor periphery, at local tumor sites, or in lymphoid organs $(31,32)$. Furthermore, Foxp $3^{+} \mathrm{CD} 25^{+} \mathrm{CD} 4^{+}$Tregs can be present in a tumor as a result of conversion from the $\mathrm{CD} 25^{-} \mathrm{CD} 4^{+}$population in the adoptive transfer system $(33,34)$. Therefore, $\alpha$-CTLA- 4 may have blocked this conversion such that the number of Foxp3-positive cells within the tumor was decreased in the mice subjected to adoptive transfer with $\mathrm{CD} 62 \mathrm{~L}^{\text {high }} \mathrm{T}$ cells, represented mostly by naïve $\mathrm{T}$ cells.

In agreement with our results, CTLA-4 inhibition has been found to enhance the Th1 response (35-37). van Elsas et al reported that $\mathrm{T}$ cells from mice treated with $\alpha$-CTLA- 4 in combination with a GM-CSF-producing tumor cell vaccine exhibited enhanced IFN- $\gamma$ secretion in vivo. In addition, the severity of experimental allergic encephalomyelitis, a classical Th1-mediated autoimmune disease model, is exacerbated by CTLA-4 suppression $(36,37)$. Contrary to these findings, it 
was demonstrated that engagement of CTLA-4 with B7 led to polarization of naïve $\mathrm{CD}^{+}$cells toward the Th1 subset and that the Th1 polarization was inhibited by CTLA-4 suppression in vitro (38). However, our findings support the notion that blocking CTLA-4 caused polarization of transferred naïve $\mathrm{CD}^{+} \mathrm{T}$ cells toward the Th1 subset. Differences in these studies may be explained by the use of different experimental models and by the complexity of the events that regulate $\mathrm{Th}$ cell subset polarization and interactions of the immune system with tumors.

It is not clear whether the effects of blocking CTLA-4 on Th-cell subset polarization are mediated by an effect on the transferred $\mathrm{T}$ cells or on endogenous $\mathrm{T}$ cells, as these cells cannot be distinguished within the tumor site. Although analysis of the behavior of transferred cells is important, this is a significant challenge, since in light of our findings, the efficacy of antitumor therapy and the effects on Th-cell subset polarization by $\alpha$-CTLA- 4 are determined by the state of T-cell differentiation. Recently, we reported that expansion of T cells in the presence of fibronectin $\mathrm{CH} 296$ (FN-CH296) leads to higher yields of naïve T cells, and that FN-CH296-stimulated T-cell adoptive transfer therapy was very well tolerated with a level of efficacy in a phase 1 clinical trial (39). Based on these results, we intend to conduct a clinical trial to clarify the efficacy of $\alpha$-CTLA- 4 and adoptive transfer with FN-CH296-stimulated T-cell combination therapy.

In conclusion, $\alpha$-CTLA- 4 enhances the antitumor activity of adoptive T-cell transfer therapy, and the effects are more pronounced in the context of naïve T-cell administration. CTLA-4 suppression may enhance Th1 polarization and attenuate Treg differentiation of T cells infiltrating the tumor. These findings suggest that $\alpha$-CTLA-4 and FN-CH296-stimulated T-cell adoptive transfer combination therapy holds potential as an effective antitumor clinical intervention.

\section{Acknowledgements}

The present study was partially supported by Grant-in-Aid for Scientific Research (no. 23590891 and 26460914) from the Japanese Ministry of Education, Culture, Sports, Science and Technology.

\section{References}

1. Krummel MF and Allison JP: CTLA-4 engagement inhibits IL-2 accumulation and cell cycle progression upon activation of resting T cells. J Exp Med 183: 2533-2540, 1996.

2. Alegre ML, Frauwirth KA and Thompson CB: T-cell regulation by CD28 and CTLA-4. Nat Rev Immunol 1: 220-228, 2001.

3. Chambers CA, Sullivan TJ and Allison JP: Lymphoproliferation in CTLA-4-deficient mice is mediated by costimulation-dependent activation of $\mathrm{CD}^{+}{ }^{+} \mathrm{T}$ cells. Immunity 7: 885-895, 1997.

4. Greenwald RJ, Oosterwegel MA, van der Woude D, Kubal A, Mandelbrot DA, Boussiotis VA and Sharpe AH: CTLA-4 regulates cell cycle progression during a primary immune response. Eur J Immunol 32: 366-373, 2002.

5. Waterhouse P, Penninger JM, Timms E, Wakeham A, Shahinian A, Lee KP, Thompson CB, Griesser H and Mak TW: Lymphoproliferative disorders with early lethality in mice deficient in Ctla-4. Science 270: 985-988, 1995.

6. Ribas A, Kefford R, Marshall MA, et al: Phase III randomized clinical trial comparing tremelimumab with standard-of-care chemotherapy in patients with advanced melanoma. J Clin Oncol 31: 616-622, 2013.
7. Hodi FS, O'Day SJ, McDermott DF, et al: Improved survival with ipilimumab in patients with metastatic melanoma. $\mathrm{N}$ Engl $\mathrm{J}$ Med 363: 711-723, 2010.

8. Robert C, Thomas L, Bondarenko I, et al: Ipilimumab plus dacarbazine for previously untreated metastatic melanoma. $\mathrm{N}$ Engl J Med 364: 2517-2526, 2011.

9. Grosso JF and Jure-Kunkel MN: CTLA-4 blockade in tumor models: An overview of preclinical and translational research. Cancer Immun 13: 5, 2013.

10. Mokyr MB, Kalinichenko T, Gorelik L and Bluestone JA: Realization of the therapeutic potential of CTLA-4 blockade in low-dose chemotherapy-treated tumor-bearing mice. Cancer Res 58: 5301-5304, 1998.

11. Pilones KA, Kawashima N, Yang AM, Babb JS, Formenti SC and Demaria S: Invariant natural killer T cells regulate breast cancer response to radiation and CTLA-4 blockade. Clin Cancer Res 15: 597-606, 2009.

12. Demaria S, Kawashima N, Yang AM, Devitt ML, Babb JS, Allison JP and Formenti SC: Immune-mediated inhibition of metastases after treatment with local radiation and CTLA-4 blockade in a mouse model of breast cancer. Clin Cancer Res 11: 728-734, 2005

13. Waitz R, Solomon SB, Petre EN, Trumble AE, Fassò M, Norton L and Allison JP: Potent induction of tumor immunity by combining tumor cryoablation with anti-CTLA-4 therapy. Cancer Res 72: 430-439, 2012.

14. Kwon ED, Foster BA, Hurwitz AA, Madias C, Allison JP, Greenberg NM and Burg MB: Elimination of residual metastatic prostate cancer after surgery and adjunctive cytotoxic $\mathrm{T}$ lymphocyte-associated antigen 4 (CTLA-4) blockade immunotherapy. Proc Natl Acad Sci USA 96: 15074-15079, 1999.

15. Hurwitz AA, Yu TF, Leach DR and Allison JP: CTLA-4 blockade synergizes with tumor-derived granulocyte-macrophage colonystimulating factor for treatment of an experimental mammary carcinoma. Proc Natl Acad Sci USA 95: 10067-10071, 1998.

16. Pedersen AE, Buus S and Claesson MH: Treatment of transplanted CT26 tumour with dendritic cell vaccine in combination with blockade of vascular endothelial growth factor receptor 2 and CTLA-4. Cancer Lett 235: 229-238, 2006.

17. Met O, Wang M, Pedersen AE, Nissen MH, Buus $S$ and Claesson MH: The effect of a therapeutic dendritic cell-based cancer vaccination depends on the blockage of CTLA-4 signaling. Cancer Lett 231: 247-256, 2006.

18. Davila E, Kennedy R and Celis E: Generation of antitumor immunity by cytotoxic T lymphocyte epitope peptide vaccination, $\mathrm{CpG}$-oligodeoxynucleotide adjuvant, and CTLA-4 blockade. Cancer Res 63: 3281-3288, 2003.

19. Daftarian P, Song GY, Ali S, Faynsod M, Longmate J, Diamond DJ and Ellenhorn JD: Two distinct pathways of immuno-modulation improve potency of p53 immunization in rejecting established tumors. Cancer Res 64: 5407-5414, 2004.

20. Kocak E, Lute K, Chang X, et al: Combination therapy with anti-CTL antigen-4 and anti-4-1BB antibodies enhances cancer immunity and reduces autoimmunity. Cancer Res 66: 7276-7284, 2006.

21. Curran MA, Montalvo W, Yagita H and Allison JP: PD-1 and CTLA-4 combination blockade expands infiltrating T cells and reduces regulatory $\mathrm{T}$ and myeloid cells within B16 melanoma tumors. Proc Natl Acad Sci USA 107: 4275-4280, 2010.

22. Gattinoni L, Klebanoff CA, Palmer DC, Wrzesinski C, Kerstann K, Yu Z, Finkelstein SE, Theoret MR, Rosenberg SA and Restifo NP: Acquisition of full effector function in vitro paradoxically impairs the in vivo antitumor efficacy of adoptively transferred CD8 ${ }^{+} \mathrm{T}$ cells. J Clin Invest 115: 1616-1626, 2005.

23. Huang J, Khong HT, Dudley ME, El-Gamil M, Li YF, Rosenberg SA and Robbins PF: Survival, persistence, and progressive differentiation of adoptively transferred tumor-reactive T cells associated with tumor regression. J Immunother 28: 258-267, 2005.

24. Watanabe A, Hara M, Chosa E, Nakamura K, Sekiya R, Shimizu T and Onitsuka T: Combination of adoptive cell transfer and antibody injection can eradicate established tumors in mice - an in vivo study using anti-OX40m Ab, anti-CD25mAb and anti-CTLA4mAb-. Immunopharmacol Immunotoxicol 32: 238-245, 2010.

25. Simpson TR, Li F, Montalvo-Ortiz W, et al: Fc-dependent depletion of tumor-infiltrating regulatory $\mathrm{T}$ cells co-defines the efficacy of anti-CTLA-4 therapy against melanoma. J Exp Med 210: 1695-1710, 2013. 
26. Selby MJ, Engelhardt JJ, Quigley M, Henning KA, Chen T, Srinivasan $\mathrm{M}$ and Korman AJ: Anti-CTLA-4 antibodies of IgG2a isotype enhance antitumor activity through reduction of intratumoral regulatory T cells. Cancer Immunol Res 1: 32-42, 2013.

27. Takahashi T, Tagami T, Yamazaki S, Uede T, Shimizu J, Sakaguchi N, Mak TW and Sakaguchi S: Immunologic self-tolerance maintained by $\mathrm{CD} 25^{+} \mathrm{CD} 4^{+}$regulatory T cells constitutively expressing cytotoxic T lymphocyte-associated antigen 4 . J Exp Med 192: 303-310, 2000.

28. Curran MA and Allison JP: Tumor vaccines expressing flt3 ligand synergize with ctla-4 blockade to reject preimplanted tumors. Cancer Res 69: 7747-7755, 2009.

29. Liakou CI, Kamat A, Tang DN, Chen H, Sun J, Troncoso P, Logothetis C and Sharma P: CTLA-4 blockade increases IFN $\gamma$ producing $\mathrm{CD} 4{ }^{+} \mathrm{ICOS}^{\mathrm{hi}}$ cells to shift the ratio of effector to regulatory $\mathrm{T}$ cells in cancer patients. Proc Natl Acad Sci USA 105: 14987-14992, 2008.

30. Hodi FS, Butler M, Oble DA, et al: Immunologic and clinical effects of antibody blockade of cytotoxic T lymphocyte-associated antigen 4 in previously vaccinated cancer patients. Proc Nat Acad Sci USA 105: 3005-3010, 2008.

31. Bluestone JA and Abbas AK: Natural versus adaptive regulatory T cells. Nat Rev Immunol 3: 253-257, 2003.

32. Akbar AN, Taams LS, Salmon M and Vukmanovic-Stejic M: The peripheral generation of $\mathrm{CD} 4{ }^{+} \mathrm{CD} 25^{+}$regulatory $\mathrm{T}$ cells. Immunology 109: 319-325, 2003.

33. Chen W, Jin W, Hardegen N, Lei KJ, Li L, Marinos N, McGrady G and Wahl SM: Conversion of peripheral $\mathrm{CD}^{+} \mathrm{CD} 25^{-}$naive $\mathrm{T}$ cells to $\mathrm{CD} 4{ }^{+} \mathrm{CD} 25^{+}$regulatory $\mathrm{T}$ cells by TGF- $\beta$ induction of transcription factor Foxp3. J Exp Med 198: 1875-1886, 2003
34. Ikemoto T, Yamaguchi T, Morine Y, Imura S, Soejima Y, Fujii M, Maekawa Y, Yasutomo K and Shimada M: Clinical roles of increased populations of $\mathrm{Foxp}^{+} \mathrm{CD} 4^{+} \mathrm{T}$ cells in peripheral blood from advanced pancreatic cancer patients. Pancreas 33: 386-390, 2006.

35. van Elsas A, Hurwitz AA and Allison JP: Combination immunotherapy of B16 melanoma using anti-cytotoxic T lymphocyte-associated antigen 4 (CTLA-4) and granulocyte/macrophage colony-stimulating factor (GM-CSF)-producing vaccines induces rejection of subcutaneous and metastatic tumors accompanied by autoimmune depigmentation. J Exp Med 190: 355-366, 1999.

36. Perrin PJ, Maldonado JH, Davis TA, June CH and Racke MK: CTLA-4 blockade enhances clinical disease and cytokine production during experimental allergic encephalomyelitis. J Immunol 157: 1333-1336, 1996.

37. Karandikar NJ, Vanderlugt CL, Walunas TL, Miller SD and Bluestone JA: CTLA-4: A negative regulator of autoimmune disease. J Exp Med 184: 783-788, 1996.

38. Ouchi N, Kihara S, Arita Y, et al: Novel modulator for endothelial adhesion molecules: Adipocyte-derived plasma protein adiponectin. Circulation 100: 2473-2476, 1999.

39. Ishikawa T, Kokura S, Enoki T, et al: Phase I clinical trial of fibronectin $\mathrm{CH} 296$-stimulated T cell therapy in patients with advanced cancer. PLoS One 9: e83786, 2014. 